\title{
NEIBURG, Federico (Org.). Conversas etnográficas haitianas.
}

\section{Nadège Mézié}

\section{(2) OpenEdition \\ 1 Journals}

Edição electrónica

URL: http://journals.openedition.org/aa/6713

DOI: 10.4000/aa.6713

ISSN: 2357-738X

Editora

Programa de Pós-Graduação em Antropologia Social (UnB)

Edição impressa

Paginação: 341-345

ISSN: 0102-4302

Refêrencia eletrónica

Nadège Mézié, «NEIBURG, Federico (Org.). Conversas etnográficas haitianas.», Anuário Antropológico [Online], v.45 n.3 | 2020, posto online no dia 16 setembro 2020, consultado o 28 abril 2021. URL: http:// journals.openedition.org/aa/6713 ; DOI: https://doi.org/10.4000/aa.6713

\section{(c) (i) (9)}

Anuário Antropológico is licensed under a Creative Commons Atribuição-Uso Não-Comercial-Proibição de realização de Obras Derivadas 4.0 International. 


\title{
NEIBURG, Federico (Org.). Conversas etnográficas haitianas. Rio de Janeiro: Papéis Selvagens, 2019. 337 p.
}

\author{
Nadège Mézié • Universidade Estadual de Campinas - Brasil
}

Doutora em Antropologia pela Universidade Paris Descartes e atualmente pós-doutoranda pelo programa Capes-Print na Faculdade de Educação da Universidade Estadual de Campinas (Unicamp). Realiza pesquisas na área da antropologia da religião e da antropologia da violência, com trabalhos de campo no Haiti desde 2005 e entre migrantes haitianos no Brasil desde 2019. 
Nos últimos 15 anos, as relações entre Brasil e Haiti se intensificaram. Isto por duas razões principais: o Brasil comandou a missão militar de pacificação das Nações Unidas no Haiti, a MINUSTAH (2004-2017), e após o terremoto de 2010, passou definitivamente a fazer parte dos destinos migratórios para haitianos. $\mathrm{O}$ estreitamento de vínculos entre os dois países deve também ser lido à luz do cenário internacional que, nas últimas décadas, viu emergir novos eixos de circulação de pessoas e um aumento das transações e projetos de cooperação internacional Sul-Sul. O livro Conversas etnográficas haitianas, coordenado por Federico Neiburg, é ao mesmo tempo produto e testemunha dessa história recente, dessa aproximação entre Haiti e Brasil ainda em curso e feita de tensões, fascinações, rejeição e de tentativas de compreensão mútua.

A coletânea é fruto de um trabalho coletivo de pesquisa que envolveu jovens pesquisadores e pesquisadores seniores, brasileiros e haitianos (estabelecidos no Brasil, no Haiti ou nos Estados Unidos) e grupos de pesquisa de duas universidades brasileiras (Unicamp e UFRJ). As "conversas" do título refletem o ambiente de trabalho: estadias em campo em equipe e trocas acadêmicas contínuas desde então. O resultado nos lembra quanto o conhecimento científico é raramente o produto do trabalho de um indivíduo isolado, mas se constrói a partir de diálogos mais ou menos institucionalizados entre pares (conversas informais, debates nos grupos de pesquisa, cursos, colóquios, avaliações de artigos, leituras de texto à distância). O livro oferece aos leitores de língua portuguesa um conjunto de pesquisas etnográficas realizadas em diferentes regiões do Haiti, em áreas rurais ou urbanas, mas também nos Estados Unidos e em vários países da América Latina por onde haitianos passam ou se estabelecem. Alguns textos revisitam temas clássicos da antropologia do Caribe (Família, Feitiço, Ancestrais, Diáspora, Comércio, Misturas), outros entram em terrenos menos explorados (Sangue, Dinheiro, Frustração). Segundo Neiburg, no entanto, o objetivo não é "oferecer um guia para compreender o Haiti, ou de dar um 'panorama' do país e dos seus dilemas” (p. 23), mas sim mostrar o diálogo construído pelos pesquisadores entre si e em torno do projeto (todos os autores mencionam outros textos da coletânea), dos pesquisadores com seus interlocutores (todos propõem análises que partem de expressões ou do ponto de vista dos interlocutores) e dos pesquisadores com a literatura acadêmica produzida por autores haitianos (como Gérard Barthélémy, Michel Laguerre, Micheline Labelle, Michel-Rolph Trouillot, Louis Maximillien, entre outros).

O livro é composto de uma introdução, nove "conversas" (capítulos), um posfácio e um apêndice. Na introdução, Neiburg apresenta os protagonistas da empreitada científica: além dele, os professores Omar Ribeiro Thomaz (que já desenvolvia pesquisas no país), Lygia Sigaud, José Renato Baptista, Natacha Nicaise e Louis Herns Marcelin, e jovens antropólogos que descobriam o métier em território haitiano (os brasileiros Flavia Dalmaso, Pedro Braum, Rodrigo Bulamah, Ana Fiod, Felipe Evangelista e o haitiano Handerson Joseph, todos autores de capítulos do livro). A introdução traz também elementos reflexivos sobre as condições do fazer etnográfico num país submetido à ingerência internacional. 
O primeiro capítulo, escrito por Louis Herns Marcelin, antropólogo haitiano estabelecido nos Estados Unidos, tem por tema o "Sangue". O texto é denso e baseia-se em trabalhos de campo que se estendem por dez anos, tanto no Haiti quanto entre membros da diáspora haitiana na Flórida. O sangue, como Françoise Héritier já havia observado, é um operador metafórico e simbólico por excelência. Marcelin trata das concepções nativas de família e poder e investiga as conexões entre poderes autocráticos, como o dos Duvalier (pai e filho), e o sacrifício. Ele defende a ideia de que é preciso voltar à história das plantations e da escravidão para entender a "política de sangue" contemporânea. Ao aproximar antropologia e história, Marcelin inscreve-se numa tradição da antropologia do Caribe que já mostrou suas virtudes heurísticas, que se pense em Michel-Rolph Trouillot, Sidney Mintz ou Stephan Palmié. No segundo capítulo, “Família”, Flavia Dalmaso busca entender o ditado que circula entre camponeses da região de Jacmel "não se come quiabo apenas com um dedo (yon sèl dwèt pa manje kalalou)". Ela mostra que tudo o que acontece nas casas e em seus terrenos (lakou), assim como as relações de vizinhança e aquelas tecidas com os espíritos, contribuem para definir os contornos da "família", para além dos laços "de sangue".

Em "Dinheiro", terceiro capítulo, Neiburg, especialista em antropologia econômica, interessa-se pelo pluralismo monetário no Haiti. Nas transações cotidianas coexistem a Gourde (moeda nacional), o Dólar americano e o "Dolar haitiano", uma moeda imaginária, que não se materializa em cédulas, e é usada somente como unidade de conta (um "Dólar haitiano" vale 5 Gourdes). Neiburg mostra que o uso da escala de $5(5,10,25,50,100$, etc.) para contas tem raízes na história colonial do país; e a partir de observações na favela de Bel Air, onde fica um dos principais mercados ao ar livre de Porto Príncipe, descreve os usos sociais diferenciados das moedas. No quarto capítulo, também dedicado à economia, Felipe Evangelista trata do "Comércio", objeto que os estudos de Sidney Mintz ajudaram a tornar clássico. Evangelista descreve com riqueza de detalhes a trajetória de uma comerciante na fronteira Haiti-República Dominicana, retraçando desde a sua aprendizagem da profissão, quando criança, acompanhando a mãe, até sua velhice e o momento de "desaceleração" de sua atividade comercial. Um caso singular que dá acesso às modalidades concretas do comércio transfronteiriço.

Na quinta "conversa", Pedro Braum reflete sobre violência e segurança a partir de um termo que muitos jovens das favelas usam: "Frustração”. Atento às emoções nas relações violentas, o autor, que é também o coordenador de uma ONG atuando em Bel Air, explica que muitas baz, associações de moradores, mesclam atividades culturais, assistenciais, políticas e criminosas e podem funcionar como gangues. $\mathrm{O}$ texto relata o confronto entre duas delas e sugere que para os integrantes, "a gestão da frustração é reivindicada como modo de possibilitar a paz” (p. 157).

Um dos debates mais antigos e animados da antropologia e da história do Caribe é aquele que reflete sobre o que o encontro violento de diferentes mundos nas ilhas da região produziu em termos de identidade: hibridez, crioulização, mestiçagem, sincretismo? No sexto capítulo, José Renato Baptista, apoiando-se nas interpretações nativas, escolhe o termo "Misturas". O autor descreve assim a 
combinação de elementos protestantes, católicos e vodu em dois cultos dedicados à Virgem Maria que ele observa, um em Pétionville e outro no Norte do país. Ainda no campo da religião, Ana Fiod, no capítulo "Feitiço", relata como crianças do sul do Haiti se protegem contra o lougawou (ser humano que se transforma em animal para comer pessoas, crianças sobretudo). Compreender a religião através do aprendizado e das práticas das crianças é raro, o que torna este estudo particularmente bem-vindo. Ao dar longamente a palavra às crianças, a autora também nos permite aceder à maneira como elas interpretam o mundo e seus relacionamentos com os adultos.

Handerson Joseph, no capítulo "Diáspora”, propõe uma análise que ele qualifica de pragmática deste termo. São repertoriados seus diferentes usos por haitianos vivendo no país ou fora: "ele é utilizado (...) como substantivo, adjetivo e verbo para conjugar, designar e qualificar pessoas, casas, objetos, dinheiro, ações e formas de ser e de viver" (p. 255). O último capítulo, “Ancestrais", escrito por Rodrigo Bulamah, combina história e antropologia. Bulamah interessa-se pela figura histórica do rei Christophe e suas realizações monumentais (Palais Sans Souci e Citadelle La Ferrière). Mas, ao invés de investigar fatos históricos, o autor procura compreender a maneira como seus interlocutores narram e de certa forma "praticam" a história, ou seja, trata da "produção da história (...) por pessoas comuns" (p. 264).

O livro se encerra com um curto posfácio e um apêndice. No posfácio, Omar Ribeiro Thomaz apresenta, com a empolgação e o brio que o caracterizam, alguns nomes da "extraordinária biblioteca haitiana" (p. 289), como Jean-Price Mars, Thomas Madiou, Anténor Firmin, Jacques Roumain, e destaca o quanto a confrontação entre esses trabalhos haitianos e os clássicos brasileiros é estimulante. No apêndice, juntam-se a Thomaz, Lygia Sigaud e Federico Neiburg para retomar o evento que está na origem do "projeto Haiti": a fundação do Instituto Interuniversitário de Pesquisas e Desenvolvimento, INURED, no Haiti, em 2007. Esses dois acréscimos esclarecem, de certa maneira, o pano de fundo e as razões da existência do livro.

Conversas etnográficas haitianas é um livro "crioulo" à sua maneira, que honra a etnografia e o espírito de diálogo e a comparação. A formação ou atuação no Brasil da maior parte dos autores os permite fazer, em seus textos, uma confrontação que me pareceu frutífera entre o que se produz no e sobre o Brasil, e o que se produz no e sobre o Caribe. Da mesma forma, o diálogo entre os autores e suas pesquisas merece ser destacado. A crítica ou ressalva que poderíamos emitir seria, justamente, a de desejar que esse movimento fosse intensificado. A situação das religiões afro-brasileiras e aquela das "misturas" no vodu e nos cristianismos haitianos poderia ser mais explorada, por exemplo; assim como poderiam, a meu ver, ser mais mobilizadas as reflexões sobre campesinato no Brasil. Alguns textos também ganhariam ao incorporar referências mais recentes sobre o tema que abordam. Sentimos, assim, que os autores não tenham, de certa forma, ido ainda mais longe no propósito inicial que se deram. Isto posto, e lembrando como a literatura em língua portuguesa sobre o Haiti e sobre o Caribe de maneira geral é 
Nadège Mézié

bastante rara, esses pontos nos fazem antes de mais nada esperar que as conversas continuem! E aguardar a chegada de um segundo volume.

Recebido: $21 / 04 / 2020$

Aprovado: 08/05/2020 